\title{
UPAYA MENINGKATKAN HASIL BELAJAR MATEMATIKA MELALUI PENERAPAN STRATEGI PEMBELAJARAN KOOPERATIF TIPE QUICK ON THE DRAW
}

\author{
Ika Wirahmat ${ }^{1}$, Iwansyah $^{2}$, Dusalan $^{* 1}$ \\ ${ }^{1}$ Program Studi Pendidikan Matematika, STKIP Bima \\ ${ }^{2}$ Guru Matematika, SMAN 3 Kota Bima \\ "Email korespondensi: dusalanbima84@gmail.com
}

\begin{abstract}
ABSTRAK
Tujuan penelitian ini adalah untuk mengetahui meningkatnya hasil belajar matematika siswa kelas VIII.A SMP Negeri 3 Wera setelah diterapkan strategi pembelajaran Kooperatif tipe Quick On The Draw pada materi relasi dan fungsi. Penelitian ini adalah penelitian tindakan kelas (PTK). Pendekatan ini menerapkan dua pendekatan yaitu kualitatif dan kuantitatif. Data kualitatifnya adalah data aktivitas siswa dan aktivitas guru sedangkan data kuantitatifnya adalah data hasil belajar siswa.Penelitian ini dilakukan sebanyak dua siklus. Siklus I hasil belajarnya73,08\% siswa mendapat nilai minimal 65, aktivitas belajar siswa berada pada skor 22 dengan kategori kurang aktif dan aktivitas guru berada pada skor 19 dengan kategori aktif. Sedangkan siklus II hasil belajarnya 88,64\% siswa mendapat nilai minimal 65, aktivitas belajar siswa berada pada skor 31 dengan kategori sangat aktif dan aktivitas guru berada pada skor 23 sangat aktif. Hal ini menunjukkan adanya peningkatan secara signifikan dari siklus I kesiklus II. Jadi penerapan strategi pembelajaran kooperatif tipe Quick On The Draw dapat meningkatkan aktivitas dan hasil belajar siswa pada materi Relasi dan Fungsi di kelas VIII.A SMP Negeri 3 Wera tahun pelajaran 2019/2020.
\end{abstract}

Kata kunci: penerapan quick on the draw, hasil belajar, relasi dan fungsi.

\begin{abstract}
The purpose of this study was to determine the increase in mathematics learning outcomes of class VIII.A students of SMP Negeri 3 Wera after implementing the Quick On The Draw cooperative learning strategy in relation and function material. This research is a classroom action research. This approach applies two approaches, namely qualitative and quantitative. The qualitative data is student activity data and teacher activity, while the quantitative data is student learning outcomes data. This research was conducted in two cycles. The first cycle of learning outcomes $73.08 \%$ of students got a minimum score of 65 , student learning activities were at a score of 22 in the less active category and teacher activities were at a score of 19 with the active category. While the second cycle of learning outcomes $88.64 \%$ of students got a minimum score of 65 , student learning activities were at a score of 31 in the very active category and teacher activities were at a score of 23 very active. This shows a significant increase from cycle I to cycle II. So the application of the Quick On The Draw type of cooperative learning strategy can increase student activity and learning outcomes on Relations and Function material in class VIII.A SMP Negeri 3 Wera in the 2019/2020 academic year.
\end{abstract}


Keywords: application of quick on the draw, learning outcomes, relationships and functions.

\section{PENDAHULUAN}

Berdasarkan hasil observasi awal dengan guru mata pelajaran matematika kelas VIII.A SMP Negeri 3 Wera, terungkap bahwa SMP Negeri 3 Wera sudah memberlakukan Kurikulum 2013 dengan menerapkan metode/model yang berlaku pada Rencana Pelaksanaan Pembelajaran (RPP), namu dalam pelaksanaannya masih terdapat siswa yang kurang antusias dalam mengikuti pelajaran. Di sisi lain, guru masih banyak menggunakan metode belajar yang belum mengaktifkan siswa secara penuh, salah satunya adalah metode ceramah. Kebanyakan siswa tidak mampu menyesuaikan diri dengan strategi yang digunakan oleh guru dan masih terdapat ketidakmandirian siswa dalam mengerjakan soal sehingga timbul hambatan belajar (learning obstacle). Sebagai salah satu sumber ilmu, peran guru dalam merancang pembelajaran yang menarik dan menarik mudah diterima siswa merupakan salah satu kunci dalam proses pembelajaran (Mulyadin, 2019).

Belajar kelompok dalam sebuah kelas sangat membutuhkan suatu pengaturan dan pengelolaan kelas yang kooperatif, dimana siswa terbentuk dalam kelompok yang heterogen misalnya pintar, tidak pintar, kaya, miskin, beberapa suku, bahasa dan jenis kelamin. Belajar adalah proses yang ditandai dengan adanya perubahan pada diri seseorang sebagai proses hasil belajar dapat ditunjukkan dalam berbagai bentuk seperti perubahan pengetahuannya, pemahamannya, sikap dan tingkah lakunya, keterampilannya, kecakapan dan kemampuannya, daya reaksinya, daya penerimaannya dan aspek lain yang ada pada indvidu (Sudjana: 2004). Hal ini menjadikan bahwa berhasil tidaknya suatu proses kegiatan pembelajaran bergantung pada kemampuan kreativitas guru menciptakan proses belajar yang sedemikian rupa sehingga dapat merangsang siswa untuk belajar secara aktif (Slameto dalam Sowanto, 2018).

Strategi yang digunakan harus beragam agar siswa tidak bosan, Mencermati keadaan tersebut, Guru mata pelajaran seharusnya mengetahui psikologis siswa dan meningkatkan hubungan emosional pada siswa sebelum menentukan strategi atau pendekatan yang digunakan. Diantara macam strategi dan pendekatan, strategi pembelajaran kooperatif tipe Quick On The Draw merupakan salah satu yang bisa diterapkan dalam penelitian ini. Strategi Pembelajaran Kooperatif Tipe Quick On The Draw memberikan pengalaman mengenai tentang macam-macam keterampilan membaca yang didorong oleh kecepatan aktivitas, ditambah belajar mandiri dan kecakapan ujian yang lain. Hal ini sesuai dengan yang 
diungkapkan Johnson \& Halubec (2010) bahwa pembelajaran kooperatif adalah proses belajar mengajar yang melibatkan penggunaan kelompok-kelompok kecil yang memungkinkan siswa untuk bekerja secara bersama-sama di dalamnya guna memaksimalkan pembelajaran mereka sendiri dan pembelajaran satu sama yang lain. Suprijono (2011:61) juga mengungkapkan bahwa model pembelajaran kooperatif dikembangkan untuk mencapai setidak-tidaknya tiga tujuan pembelajaran penting, yaitu hasil belajar akademik, penerimaan terhadap keragaman dan pengembangan keterampilan sosial.

Pembelajaran dengan penerapan Strategi Pembelajaran Kooperatif Tipe Quick On The Draw memperhatikan kerja sama, sehingga dapat menciptakan hubungan sosial antara siswa dengan siswa lainnya dan pembelajaran secara kooperatif dengan sendirinya tercipta tapi tetap memfokuskan pada pribadi siswa agar dapat memperoleh standar yang tinggi. Penilain yang dilakukan tidak hanya melihat pada satu sisi, selain hasil proses pembelajaran juga berperan dalam penilaian terhadap siswa dengan demikian dapat membantu siswa untuk tumbuh dan berkembang. Lebih lanjut menurut Ginnis (2016), strategi Pembelajaran Kooperatif Tipe Quick On The Draw dapat mendorong aktivitas kerja kelompok, sehingga siswa dapat menyadari bahwa pembagian tugas lebih produktif daripada menduplikasi tugas. Kegiatan ini membantu siswa untuk membiasakan diri mendasarkanbelajar pada sumber bukan guru.

Dari uraian di latar belakang, maka peneliti tertarik melakukan penelitian tentang: "Upaya meningkatkan hasil belajar matematika melalui penerapan strategi pembelajaran kooperatif tipe Quick On The Draw pada pokok bahasan relasi dan fungsi pada siswa kelas VIII.A SMP Negeri 3 Wera tahun pelajaran 2019/2020”.

\section{METODE PENELITIAN}

Jenis penelitian ini adalah Penelitian Tindakan Kelas (PTK) atau Classroom Action (CAR). Penelitian tindakan kelas merupakan suatu pencermatan terhadap kegiatan belajar berupa sebuah tindakan, yang sengaja dimunculkan dan terjadi dalam sebuah kelas secara bersama (Arikunto, 2010). Rancangan penelitian ini mengacu pada model penelitian yang dikemukakan oleh Kemmis dan Mc. Taggart (Arikunto, 2010) yang terdiri atas 4 tahapan yaitu Perencanaan, Pelaksanaan tindakan, Observasi/Evaluasi dan Refleksi. 
Adapun tahapan siklusnya adalah sebagai berikut:

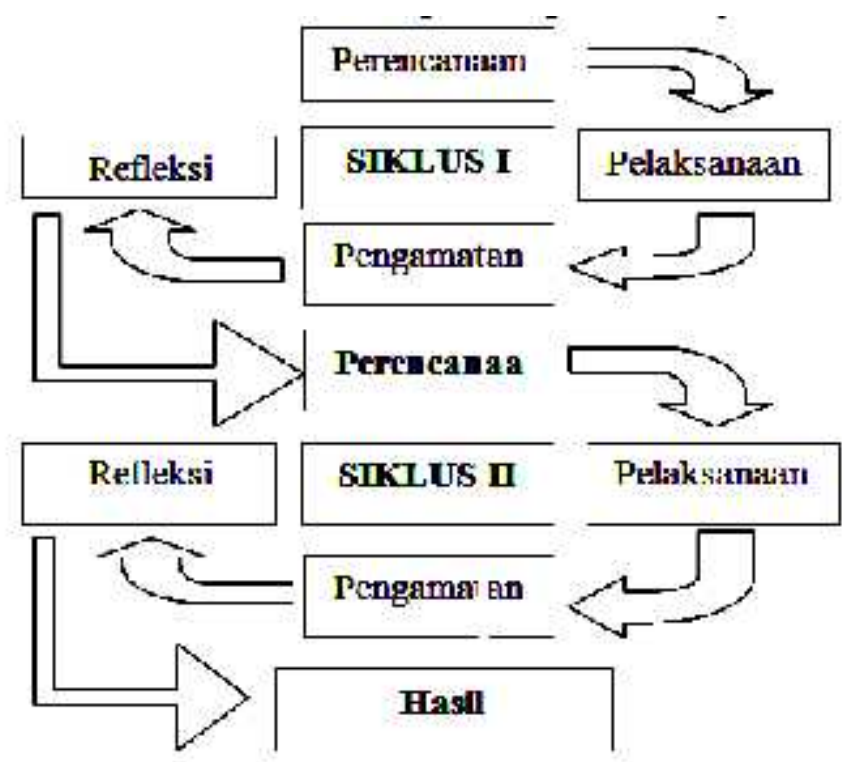

Gambar 1. Penelitian Tindakan Kelas (PTK) model Kemmis dan Mc taggart

Penelitian ini dilaksanakan di kelas VIII.A SMP Negeri 3 Wera Tahun 2019/2020. Dengan Subyek penelitiannya adalah siswa-siswi kelas VIII.A SMP Negeri 3 Wera Tahun Pelajaran 2019/2020 dengan Objek penelitian nya adalah peningkatan hasil belajar siswa pada Relasi dan Fungsi dengan menerapkan model pembelajaran Kooperatif tipe Quick On The Draw.

Pengelolaan data merupakan satu langkah yang sangat penting dalam kegiatan penelitian. Adapun data yang akan dianalisis oleh peneliti dalam penelitian ini adalah data aktivitas pembelajaran dan data hasil refleksi. Adapun indikator keberhasilan dalam penelitian tindakan kelas ini dapat dilihat dari aktivitas belajar siswa dikatakan meningkat apabila minimal berkategori cukup aktif dan mengalami peningkatan rata-rata skor pada setiap siklus, sedangkan aktivitas guru dikatakan meningkat apabila berkategori baik dan mengalami peningkatan rata-rata skor pada setiap siklusnya. Hasil belajar siswa dikatakan meningkat jika presentase ketuntasan belajar siswa minimal $85 \%$ siswa mencapai nilai $\geq 65$. 


\section{HASIL DAN PEMBAHASAN}

Dalam pelaksanaannya, penelitian ini dilaksanakan dalam dua siklus dengan jadwal penelitian disesuaikan dengan jadwal pembelajaran yang ditetapkan di SMP Negeri 3 Wera.

\section{Siklus 1}

\section{Perancangaan tindakan}

Pada tahap ini, peneliti mengawali dengan penentuan materi yang akan disajikan objek penelitian bersama guru pelajaran matematika yang bersangkutan. Setelah berdiskusi dengan guru yang, ditetapkan kelas VIII.A sebagai subjek penelitian. Tindakan selanjutnya adalah peneliti mempersiapkan perangkat pembelajaran dan instrumen penelitian yang akan digunakan.

\section{Pelaksanaan tindakan}

Pada pertemuan 1 dan 2 siklus 1, penelitian dilaksanakan berdasarkan Rencana Pelaksanaan Pembelajaran yang dirancang pada tahap sebelumnya.

\section{Observasi}

Pada penelitian ini observasi dilakukan pada aktivitas guru dan aktivitas siswa dalam pembelajaran. Pelaksanaan observasi aktivitas guru meliputi mulai dari pelaksanaan pembelajaran pada kegiatan awal, kegiatan inti dan kegiatan penutup yang terdiri dari 6 indikator sebagai berikut:

Tabel 1. Hasil Aktivitas Guru Melalui Strategi Pembelajaran Quick On The Draw Siklus I

\begin{tabular}{lll}
\hline \multicolumn{3}{c}{ Hasil Aktifitas Guru } \\
\hline Jumlah skor indikator & 18 & 20 \\
Total skor indikator & 38 & \\
Banyak indikator & 12 \\
Rata-rata skor & 3,17 \\
Kategori & Baik \\
\hline
\end{tabular}

Dari tabel diatas dapat dilihat bahwa aktivitas guru pada siklus I melalui pembelajaran strategi Quick On The Draw, aktivitas yang dilakukan oleh guru yaitu sebesar 40 berada pada kriteria "Baik". 
Adapun hasil observasi aktifitas siswa pada siklus I, dapat dilihat seperti pada tabel di bawah 2 di bawah ini.

Tabel 2. Hasil Aktivitas Siswa Melalui Penerapan Strategi Quick On The Draw pada Siklus I

\begin{tabular}{lll}
\hline \multicolumn{3}{c}{ Hasil Aktifitas Siswa } \\
\hline Jumlah skor indikator & 22 & 27 \\
Banyak skor indikator & 49 & \\
Banyaknya indikator & 20 & \\
Rata-rata skor & 2,45 & \\
Kategori & Cukup aktif \\
\hline
\end{tabular}

Dari tabel diatas dapat dilihat bahwa aktivitas siswa pada siklus I melalui pembelajaran strategi Quick On The Draw, aktivitas yang dilakukan oleh siswa sebesar 49 berada pada kategori “Cukup aktif”. lebih jelasnya dapat dilihat pada lampiran 22 dan lampiran 23.

\section{Evaluasi}

Melalui analisis evaluasi belajar nilai rata-rata siswa dan ketuntasan belajar siswa siklus 1 dapat dilihat pada tabel berikut :

Tabel 3. Hasil evaluasi siswa pada siklus I

\begin{tabular}{ll}
\hline \multicolumn{2}{c}{ Hasil Evaluasi Siswa } \\
\hline Jumlah siswa yang mengikuti tes & 26 \\
Jumlah nilai siswa & 1795 \\
Nilai rata-rata siswa & 69,04 \\
Jumlah siswa yang tuntas & 19 \\
Jumlah siswa yang tidak tuntas & 7 \\
\% ketuntasan klasikal & $73,08 \%$ \\
\hline
\end{tabular}

Dari tabel diatas dapat dilihat bahwa pada siklus I keseluruhan nilai siswa dalam usaha peningkatan hasil belajar melalui strategi pembelajaran Quick On The Draw dengan jumlah 1795 atau rata-rata 69,04. Dari tabel diatas dapat dilihat bahwa 19 orang mencapai ketuntasan secara individual. Sedangkan ketuntasan klasikal hasil belajar siswa adalah 73,08\%. Hal ini berarti ketuntasan belajar siswa kelas VIII.A SMP Negeri 3 Wera secara klasikal belum mencapai $85 \%$ kriteria ketuntasan minimal yang ditetapkan yaitu 65. Untuk itu dalam penelitian ini peneliti akan memperbaiki kegagalan yang dialami siswa melalui penelitian tindakan kelas dengan melanjutkan tindakan pada siklus ke II. 


\section{Refleksi}

Tahap refleksi merupakan kegiatan yang dilakukan untuk memperbaiki hasil observasi pada siklus sebelumnya. Data hasil observasi siklus I adalah:

1. Kurangnya motivasi dari guru untuk siswa

2. Siswa baru beradaptasi dengan strategi Quick On The Draw

3. Pada saat proses pembelajaran terlihat beberapa orang siswa yang tidak memperhatikan penjelasan guru

4. Pada saat kerja kelompok masih ada siswa yang tidak bekerja sama dengan anggota kelompoknya

Adapun langkah-langkah perbaikan yang dilakukan adalah:

1. Guru hendaknya memotivasi siswa dalam memberikan penjelasan pembelajaran

2. Guru harus bisa menjelaskan secara jelas proses pembelajaran strategi Quick On The Draw pada siswa

3. Guru memberikan motivasi kepada siswa agar siswa focus pada pelajaran yang diberikan oleh guru

4. Guru membimbing siswa untuk lebih aktif dalam bekerjasama dengan anggota kelompok.

Pada siklus I hasil observasi dapat dilihat bahwa masih banyak kekurangan yang harus diperbaiki.Kekurangan pada siklus I di adakan refleksi untuk memperbaiki kekurangan sesuai dengan hasil observasi siklus I untuk dilaksanakan pada siklus II.

\section{Siklus II}

\section{Perancangaan tindakan}

Pada tahap ini, peneliti mengawali dengan berdiskusi dengan guru terkait hasil refleksi siklus 1. Tindakan selanjutnya sama seperti pada siklu adalah peneliti mempersiapkan perangkat pembelajaran dan instrumen penelitian yang akan digunakan.

\section{Pelaksanaan tindakan}

Pelaksanaan tindakan pada siklus II masih sama dengan tindakan yang dilakukan pada siklus I yaitu berdasarkan RPP yang telah direvisi sesuai dengan hasil refleksi pada siklus I. 


\section{Observasi}

Pada penelitian ini observasi dilakukan pada aktivitas guru dan aktivitas siswa dalam pembelajaran. Pelaksanaan observasi aktivitas guru meliputi mulai dari pelaksanaan pembelajaran pada kegiatan awal, kegiatan inti dan kegiatan penutup yang terdiri dari 10 indikator sebagai berikut :

Tabel 4. Hasil Aktivitas Guru Melalui Strategi Pembelajaran Quick On The Draw Siklus II

\begin{tabular}{lll}
\hline \multicolumn{3}{c}{ Hasil Aktifitas Guru } \\
\hline Jumlah skor indikator & 22 & 23 \\
Total skor indikator & 45 & \\
Banyak indikator & 12 & \\
Rata-rata skor & 3,75 & \\
Kategori & Sangat baik \\
\hline
\end{tabular}

Adapun hasil observasi aktifitas siswa pada siklus II, dapat dilihat seperti pada tabel di bawah 5 di bawah ini.

Tabel 5. Hasil Aktivitas Siswa Melalui Penerapan Strategi Quick On The Draw pada Siklus II

\begin{tabular}{lll}
\hline \multicolumn{2}{c}{ Hasil Aktifitas Siswa } \\
\hline Jumlah skor indikator & 28 & 31 \\
Banyak skor indikator & 59 & \\
Banyaknya indikator & 20 & \\
Rata-rata skor & 2,95 & \\
Kategori & Sangat Aktif \\
\hline
\end{tabular}

Dari tabel diatas dapat dilihat bahwa aktivitas siswa pada siklus II melalui pembelajaran strategi Quick On The Draw, dimana aktivitas yang dilakukan oleh siswa sebesar 59 pada kategori "sangat aktif".

\section{Evaluasi}

Setelah dilakukan observasi baik aktivitas guru maupun aktivitas siswa pada pembelajaran strategi Quick On The Draw, selanjutnya dilakukan evaluasi. Adapun analisis evaluasi belajar nilai rata-rata siswa dan ketuntasan belajar siswa dapat dilihat pada tabel 6 . 
Tabel 6. Hasil Evaluasi Siswa Pada Siklus II

\begin{tabular}{ll}
\hline \multicolumn{2}{c}{ Hasil Evaluasi Siswa } \\
\hline Jumlah siswa yang mengikuti tes & 26 \\
Jumlah niai siswa & 2120 \\
Nilai rata-rata siswa & 81,54 \\
Jumlah siswa yang tuntas & 23 \\
Jumlah siswa yang tidak tuntas & 3 \\
$\%$ ketuntasan klasikal & $88,46 \%$ \\
\hline
\end{tabular}

Dari tabel diatas dapat dilihat bahwa pada siklus II keseluruhan nilai siswa dalam usaha peningkatan hasil belajar melalui strategi pembelajaran Quick On The Draw dengan jumlah 2120 atau rata-rata 81,54. Dari tabel diatas diketahui bahwa 23 orang mencapai ketuntasan secara individual. Sedangkan ketuntasan klasikal hasil belajar siswa adalah 88,46\%. Hal ini berarti ketuntasan belajar siswa kelas VII.A SMP Negeri 3 Wera secara klasikal sudah mencapai $85 \%$ kriteria ketuntasan minimal yang ditetapkan yaitu 65. Untuk itu dalam penelitian ini peneliti akan berhenti sampe siklus ke II dan tidak dilanjutkan ke siklus selanjutnya.

\section{Refleksi}

Berdasarkan hasil penelitian pada siklus II yang dikemukakan diatas, maka dapat disimpulkan bahwa dari 26 orang siswa, terdapat 23 orang siswa yang tuntas, sedangkan 3 orang siswa belum tuntas atau memperoleh nilai dibawah kriteria ketuntasan minimal yang ditetapkan yaitu 65. Dengan demikian pada siklus II sudah mencapai kriteria ketuntasan klasikal sebesar $85 \%$. Dengan demikian pada siklus II ini hasil belajar siswa telah tuntas secara maksimal.

Penelitian tentang peningkatan hasil belajar siswa telah dilakukan oleh beberapa peneliti terdahulu, salah satunya Sartika \& Silviana (2018), Sowanto, dkk (2018), Nurahmi, dkk (2019), dan Hadi \& Saifullah (2019) Perbedaan penelitian terdahulu dengan peneliti adalah strategi pembelajaran dan indikator yang digunakan. Sedangkan persamaannya terletak pada hasil yang dicapai yaitu terdapat peningkatan indikator keaktifan belajar Siswa. 


\section{KESIMPULAN}

Berdasarkan hasil penelitian dan pembahasan, maka dapat ditarik beberapa kesimpulan sebagai berikut:

1. Penerapan strategi pembelajaran kooperatif tipe Quick On The Draw pada materi relasi dan fungsi dapat meningkatkan aktivitas belajar siswa khususnya kelas VIII.A SMP Negeri 3 Wera tahun pelajaran 2019/2020 hal ini dapat dibuktikan dengan hasil analisis lembar observasi aktivitas siswa dari siklus I dengan jumlah 22 dengan kategori "kurang aktif”, sedangkan pada siklus II meningkat menjadi 31 dengan kategori “aktif”. Sedangkan lembar observasi guru pada siklus I dengan jumlah 19 dengan kategori “aktif” sedangkan pada siklus ke II meningkat menjadi 23 dengan kategori "sangat aktif”.

2. Penerapan strategi pembelajaran kooperatif tipe Quick On The Draw pada materi relasi dan fungsi dapat meningkatkan hasil belajar siswa hal ini dapat dilihat dari hasil evaluasi belajar siswa dari siklus I mencapai 73,08\% siswa tuntas secara klasikalsedangkan pada siklus ke II meningkat menjadi 88,46\% (memenuhi syarat $\geq 85 \%$ siswa memperoleh nilai 65), atau dengan kata lain bahwa dalam siklus II ini siswa kelas VII.A SMP Negeri 3 Wera tahun ajaran 2019/2020 telah tuntas hasil belajarnya secara klasikal.

\section{REKOMENDASI}

Adapun rekomendasi yang dapat disampaikan sehubung dengan hasil penelitian ini adalah :

1. Untuk pimpinan sekolah diharapkan dapat ikut berperan aktif dalam mensosialisasikan dan menumbuh kembangkan penerapan strategi pembelajaran kooperatif tipe Quick On The Draw dalam proses pembelajaran matematika pada materi Relasi dan Fungsi agar kualitas peserta didik di lingkup sekolah tersebut dapat lebih ditingkatkan disegala aspek.

2. Pada guru matematika SMP Negeri 3 Wera diharapkan dapat menerapkan strategi pembelajaran kooperatif tipe Quick On The Draw dalam proses pembelajaran matematika pada materi Relasi dan Fungsi. 


\section{UCAPAN TERIMAKASIH}

Ucapan terima kasih kami sampaikan kepada semua pihak yang telah membantu demi kelancaran penelitian ini, terutama :

1. Bapak Kepala SMP Negeri 3 Wera, Jukran S.Pd yang bersedia memberikan ijin penelitian di sekolah yang dipimpinnya.

2. Guru mata pelajaran matematika SMP Negeri 3 Wera, Nuraini,S.Pd yang telah membantu kami dalam melaksanakan penelitian ini.

3. Pada kesempatan ini juga secara khusus penulis menyampaikan rasa terimakasih kepada seluruh pihak yang telah membantu dan memberikan dorongan maupun motivasi demi terselesainya penelitian ini.

\section{REFERENSI}

Arikunto, S. (2010). Metode peneltian. Jakarta: Rineka Cipta.

Ginnis, P. (2016). Trik \& Taktik Mengajar. Jakarta: PT Macanan Jaya Cemerlang.

Hadi, A. M., \& Saifullah, S. (2018). PENINGKATKAN KEMAMPUAN GURU MATEMATIKA DALAM MELAKSANAKAN PENELITIAN TINDAKAN KELAS MELALUI BIMBINGAN INDIVIDUAL DI SMP NEGERI 3 KOTA BIMA. SUPERMAT (JURNAL PENDIDIKAN MATEMATIKA), 2(2), 10-17.

Johnson \& Halubec. (2010). Colaborative learning. (penerjemah Narulita Yusron). Nusa media: Bandung.

Mulyadin, E. (2019, November). Developing of teaching materials for junior high school students based on ethnomathematics on traditional woven cloth (Tembe Nggoli) of Mbojo tribe. In Journal of Physics: Conference Series (Vol. 1280, No. 4, p. 042044). IOP Publishing.

Nurahmi, S., Mulyadin, E., Andang, A., \& Saifullah, S. (2019). PENERAPAN MODEL PEMBELAJARAN INQUIRI DALAM MENINGKATKAN PEMAHAMAN KONSEP SISWA KELAS VII B SMPN 2 MONTA. SUPERMAT (JURNAL PENDIDIKAN MATEMATIKA), 3(1), 51-68. 
SARTIKA, D., \& SILVIANA, D. (2018). PENERAPAN MODELPEMBELAJARAN KOOPERATIFTIPE GROUP INVESTIGATION (GI) DALAM MENINGKATKAN KOMPETENSI MATEMATIKA SISWA. SUPERMAT (JURNAL PENDIDIKAN MATEMATIKA), 2(1), 11-18.

Sowanto, S. (2018). BAHAN AJAR PADA MATERI GARIS SINGGUNG LINGKARAN DENGAN PENDEKATAN SAINTIFIK UNTUK SISWA SMP. Kalamatika: Jurnal Pendidikan Matematika, 3(1), 63-80.

Sowanto, S., Soeprianto, H., \& Hapipi, H. (2018). PENERAPAN MODEL PEMBELAJARAN THINK-TALK-WRITE UNTUK MENINGKATKAN AKTIVITAS DAN PRESTASI BELAJAR MATEMATIS SISWA MTS DARUL QURAN BENGKEL. SUPERMAT (JURNAL PENDIDIKAN MATEMATIKA), 2(2), 19.

Sudjana,N. (2004). Dasar-Dasar Proses Belajar Mengajar. Bandung: Sinar Baru.

Suprijono, Agus. 2011.Cooperatife Learning, Teori Dan Aplikasi Paikem.Yogyakarta: Pustaka Belajar 